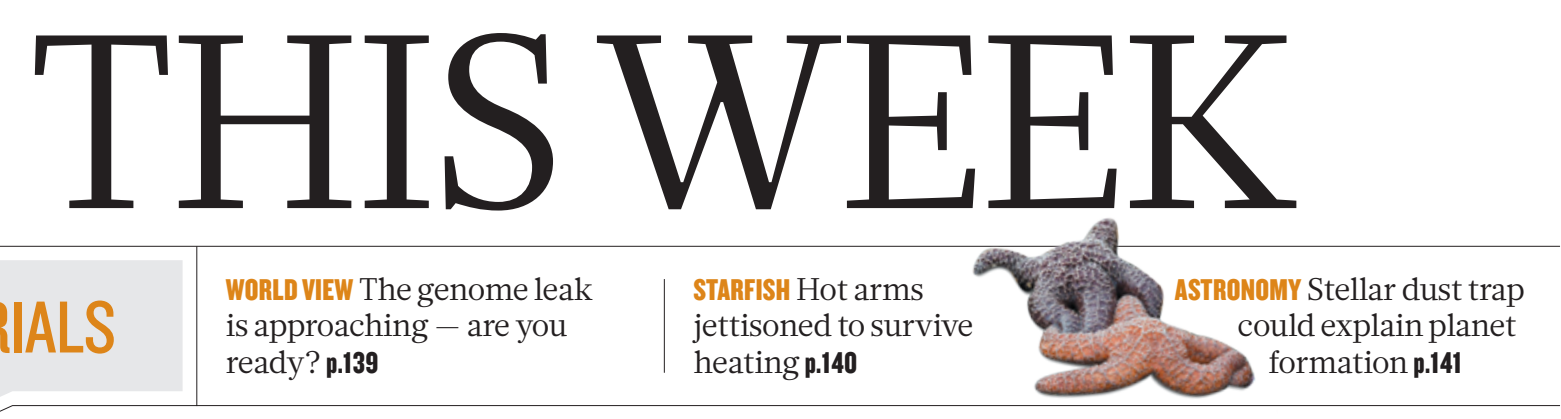

EDITORIALS is approaching - are you ready? $\mathbf{p} \mathbf{1 3 9}$ jettisoned to survive heating $\mathbf{p} .140$ could explain planet

\title{
No dishonour in depression
}

\section{The stigma associated with mental illness discourages investment in finding cures - even though the burden of the disorders on society is immense.}

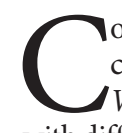

omedian and writer Ruby Wax, a regular on British television, has clinical depression. In her book published last week, Sane New World (Hodder \& Stoughton, 2013), she describes her struggles with different therapies and her fear of being 'found out.' She is not alone. A 2010 survey in Europe revealed that 38\% of people had a diagnosed mental disorder - including 7\% with major depression. The proportion is likely to be similar in all populations, even in Africa, where psychiatric disease barely features on the health agenda.

The stigma attached to such disorders means that many people do not admit to their illness. The same stigma discourages investment, so that research funding is not proportional to the distress these disorders cause. Why lobby for better treatments for depression or schizophrenia when there are 'real' diseases out there, such as cancer?

Wax has been through the catalogue of available therapies and says that she has settled on an approach known as 'mindfulness', which helps to keep her depression under control. It may seem that the various therapies are inadequate, given that initial treatment of depression fails in $60 \%$ or more of cases. It is true that more treatment options are badly needed. Yet evidence-based cognitive behavioural therapies and drugs already developed by the pharmaceutical industry can work splendidly for long periods - if they are given to the right patients.

How do you recognize the right patients? Treatment decisions tend to be based on the preferences of physicians or their patients, often with a missionary zeal that gives no credence to the idea that a personalized approach would be more appropriate. Some hold that drugs have unacceptable side effects, whereas others say that cognitive therapy wastes time if the depressed brain is not first chemically lifted. It is becoming increasingly common to offer patients both treatments at once in the belief that drugs can prepare the brain to respond to cognitive therapy. That may be so, but it is also possible that the improved response rates are simply the result of catching two different populations.

The situation would improve drastically if simple tests could be developed to predict treatment outcome. Many exploratory clinical trials are now under way to search for biomarkers in genes or in the brain itself that might be predictive. This week sees the description of the first potential biomarker for discriminating between responders and non-responders to drugs or cognitive therapy in major depressive disorder (C. L. McGrath et al. JAMA Psychiatry http://dx.doi. org/10.1001/jamapsychiatry.2013.143; 2013).

The study, led by neurologist Helen Mayberg of Emory University in Atlanta, Georgia, used positron emission tomography (PET) scans to measure metabolic activity in various brain regions of people with untreated depression (see also Nature http://doi.org/mtc; 2013). Patients were randomized into groups and treated for 12 weeks with either a commonly used antidepressant drug or cognitive behaviour therapy. The study's results were clear-cut. Below-average activity in a brain area called the right anterior insula - which is linked with depression-relevant behaviours such as emotional self-awareness and decision-making
- was associated with the patient showing a good response to cognitive behavioural therapy and a poor response to the drug. Above-average insula activity was predictive of the opposite.

This potential biomarker must still be tested in prospective clinical trials, which will assign patients to a treatment on the basis of their insula activity. It may fail. But if the biomarker comes up trumps, it
"The stigma
attached to mental disorders will fade when

treatment

becomes more effective. could be transformative for many patients who would not have to endure two or three months of treatment trial and error.

If attitudes to mental illness do not change, even a successful biomarker of this type will have a hard time being accepted by health systems that foot the bills. Unlike a simple blood test, a PET scan is inconvenient because not all physicians have easy access to the technology and, at up to US\$2,000 a shot, the procedure is not cheap. Although expensive treatments for other diseases and arguments about how to fund them are nothing new, this rational debate is harder for mental illnesses because of the irrational stigma that is attached to them.

Fifty years ago, the stigma surrounding cancer meant that physicians would sometimes lie to patients about the diagnosis from kindness. That has now faded because cancer is not always the death sentence it once was - thanks in part to the development of biomarkers that guide therapy. The stigma attached to mental disorders will also fade when treatment becomes more effective. But to break out of a vicious circle of underinvestment in a stigmatized disease area will require continued effort to get the problem recognized. This is a good week for that.

\section{Track the trackers}

\section{Oversight and public debate about access to personal data are crucial to preserving privacy.}

A ccess to phone records is all over the news at the moment, following media revelations of massive snooping by US intelligence agencies. Collecting phone records is in itself nothing new, and is legitimate - scientists have long done so for research. What is unprecedented is the government weaving together multiple huge data sets for secret state surveillance.

When researchers obtain electronic records of millions of people's calls for social science - including data on who called whom, when and from where, but not actual conversations - they must first make a strong case for why they need that information, and must comply with multiple layers of oversight and safeguards such as anonymization of 
numbers. The same goes for research use of health records or any other private personal data. And there is a good reason: to protect privacy.

Privacy concerns are at the heart of the uproar over how the US National Security Agency (NSA) has secretly required telephone companies to hand over similar phone records on almost every US resident. The US government is also vacuuming up billions of e-mails and other Internet communications from traffic outside the United States - all in the name of law enforcement and the war on terror.

What is perhaps most concerning, apart from the mind-boggling scale of the snooping, is that until last week, the very existence of these programmes was secret. Since the revelations, US President Barack Obama has defended this secrecy, on the grounds that if terrorists knew that the government was monitoring phones and the Internet, they would seek ways around the surveillance. But most terrorists probably take that as a given and - unlike most ordinary citizens already use encryption and other techniques to secure and obfuscate communication. It is a poor excuse for a lack of transparency and public oversight of such snooping. Obama asked Americans to trust the government, but history shows that 'trust us' is not good enough.

The revelations seem to vindicate many of the conclusions and recommendations of a 2008 report by the US National Research Council (NRC) - Protecting Individual Privacy in the Struggle Against Terrorists: A Framework for Program Assessment (go.nature.com/bsooux). That report addressed privacy issues raised by the Total Information Awareness programme, a research effort launched by the US Defense Advanced Research Projects Agency in 2002 to develop data mining and other technologies to link and search disparate databases, for example to try to identify suspicious patterns to detect and track terrorists.

After much controversy, that programme had its funding removed by Congress in 2003. But as the NRC report noted, this was probably a pyrrhic victory for civil liberties. It removed a focused programme subject to congressional oversight and public debate that would determine appropriate uses and safeguards. Instead, much the same work has continued in agencies across government, including the NSA, with less oversight. The report warned that this was "likely to result in little security and, ultimately, brittle privacy protection". How right it was.

Privacy matters. Yet last week, many defenders of snooping on private individuals sought to play down its significance. Several, including UK foreign secretary William Hague, trotted out tired fallacies, including that people who have nothing to hide have nothing to fear. That has long been debunked by academics; the idea is based on a misconception of what privacy is about.

Privacy is a human right, and is essential if people are to develop

"Obama asked

Americans

to trust the

government, but

history shows

that 'trust us'

isnot good

enough." autonomy. It is central to freedom of expression and association, and to preventing abuse of personal information. There are numerous examples of misuse of private data by agencies and law enforcement, including intimidation, selective character assassination, repression of dissent and wrongful arrest. Privacy is a cornerstone of a free and creative society, and is an essential defence against unwarranted social control.

Government officials in the United States and elsewhere should find the NRC report and read it carefully. It calls for "robust, independent oversight" of government data mining and surveillance to "mine the miners and track the trackers". Some data could help security efforts, the report says, but it notes that many security experts have misgivings. They question the feasibility and reliability of data mining to look for and track terrorists in massive data sets, and they raise concerns about the risk of law-abiding individuals and companies being falsely targeted.

Such surveillance is not unique to the United States. In April, a report by the United Nations' Human Rights Council warned that many countries worldwide, including democracies, are increasingly allowing intelligence and law-enforcement agencies to deploy indiscriminate and extensive surveillance of communications. That weakens or removes safeguards such as justification of individual cases of surveillance, and oversight by a neutral judicial body.

As the World View on page 139 shows, privacy and what it means in the digital age is an increasingly crucial question in the era of big data. A grown-up and open debate is needed, with trust on all sides. It has not started well.

\section{Young upstarts}

\section{Lucrative prizes emulating the Nobels bring welcome money and publicity for science.}

$\mathrm{W}$ hen a theoretical physicist who has worked on quantum field and string theory calls attention to an "interesting experiment", the experiment deserves notice. This is particularly true when that experiment is an attempt to deliver a little Hollywood glamour to physics, with an Oscars-style ceremony and gigantic cash prizes.

The US \$3-million Fundamental Physics Prize is indeed an interesting experiment, as Alexander Polyakov said when he accepted this year's award in March. And it is far from the only one of its type. As a News Feature on page 152 discusses, a string of lucrative awards for researchers have joined the Nobel Prizes in recent years. Many, like the Fundamental Physics Prize, are funded from the telephone-numbersized bank accounts of Internet entrepreneurs. These benefactors have succeeded in their chosen fields, they say, and they want to use their wealth to draw attention to those who have succeeded in science.

What's not to like? Quite a lot, according to a handful of scientists quoted in the News Feature. You cannot buy class, as the old saying goes, and these upstart entrepreneurs cannot buy their prizes the prestige of the Nobels. The new awards are an exercise in self-promotion for those behind them, say scientists. They could distort the

meritocracy of peer-review-led research. They could cement the status quo of peer-reviewed research. They do not fund peer-reviewed research. They perpetuate the myth of the lone genius.

The goals of the prize-givers seem as scattered as the criticism. Some want to shock, others to draw people into science, or to better reward those who have made their careers in research. Several want to show that leading scientists can attain the lifestyles of financiers and footballers.

As Nature has pointed out before, there are some legitimate concerns about how science prizes - both new and old - are distributed. The Breakthrough Prize in Life Sciences, launched this year, takes an unrepresentative view of what the life sciences include (see Nature 494, 402; 2013). But the Nobel Foundation's limit of three recipients per prize, each of whom must still be living, has long been outgrown by the collaborative nature of modern research - as will be demonstrated by the inevitable row over who is ignored when it comes to acknowledging the discovery of the Higgs boson. The Nobels were, of course, themselves set up by a very rich individual who had decided what he wanted to do with his own money. Time, rather than intention, has given them legitimacy.

As much as some scientists may grumble about the new awards, the financial doping that they bring to research and the wisdom of the goals behind them, two things seem clear. First, most researchers would accept such a prize if they were offered one. Second, it is surely a good thing that the money and attention come to science rather than

$\rightarrow$ NATURE.COM To comment online, click on Editorials at: go.nature.com/xhunqv go elsewhere. It is fair to criticize and question the mechanism - that is the culture of research, after all - but it is the prize-givers' money to do with as they please. It is wise to accept such gifts with gratitude and grace. 